\title{
Empowering Muscle Stem Cells for the Treatment of Duchenne Muscular Dystrophy
}

\author{
Romina L. Filippelli Natasha C. Chang \\ Department of Biochemistry, McGill University, Montréal, QC, Canada
}

\section{Keywords}

Satellite cell · Myogenesis · Muscle regeneration · Duchenne muscular dystrophy · Myopathy

\begin{abstract}
Duchenne muscular dystrophy (DMD) is a devastating and debilitating muscle degenerative disease affecting 1 in every 3,500 male births worldwide. DMD is progressive and fatal; accumulated weakening of the muscle tissue leads to an inability to walk and eventual loss of life due to respiratory and cardiac failure. Importantly, there remains no effective cure for DMD. DMD is caused by defective expression of the DMD gene, which encodes for dystrophin, a component of the dystrophin glycoprotein complex. In muscle fibers, this protein complex plays a critical role in maintaining muscle membrane integrity. Emerging studies have shown that muscle stem cells, which are adult stem cells responsible for muscle repair, are also affected in DMD. DMD muscle stem cells do not function as healthy muscle stem cells, and their impairment contributes to disease progression. Deficiencies in muscle stem cell function include impaired establishment of cell polarity leading to defective asymmetric stem cell division, reduced myogenic commitment, impaired differen-
\end{abstract}

tiation, altered metabolism, and enhanced entry into senescence. Altogether, these findings indicate that DMD muscle stem cells are dysfunctional and have impaired regenerative potential. Although recent advances in adeno-associated vector and antisense oligonucleotide-mediated mechanisms for gene therapy have shown clinical promise, the current therapeutic strategies for muscular dystrophy do not effectively target muscle stem cells and do not address the deficiencies in muscle stem cell function. Here, we discuss the merits of restoring endogenous muscle stem cell function in degenerating muscle as a viable regenerative medicine strategy to mitigate DMD.

(c) 2021 S. Karger AG, Basel

\section{Introduction}

Satellite cells, which are muscle-resident somatic stem cells, are muscle cell precursors kept in a G0-reversible quiescent, mononucleated state in their niche located between the sarcolemma and basal lamina of skeletal muscle fibers [Mauro, 1961; Yin et al., 2013]. The presence and activation of satellite cells are responsible for the regenerative capacity of adult muscle tissue 


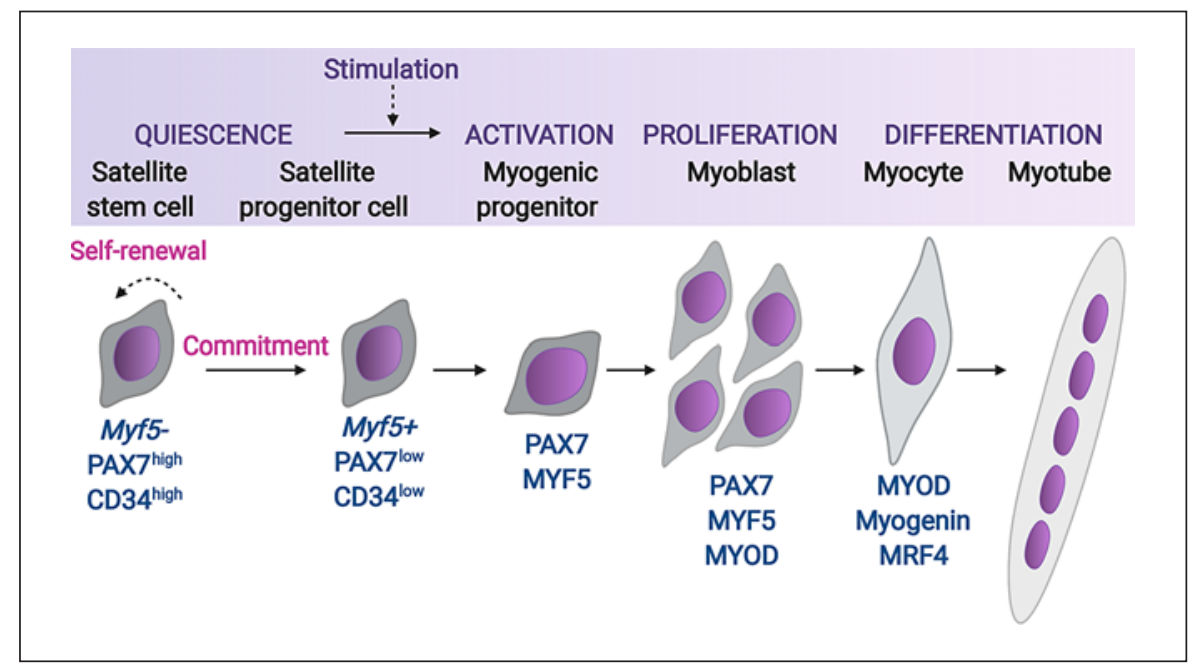

Fig. 1. Schematic of adult myogenesis. In adult skeletal muscle, satellite stem cells are kept in a reversible cell cycle-arrested state. Satellite cells are a heterogenous population of stem cells and committed progenitor cells: Myf5-, PAX $7^{\text {high }}$, and CD $34^{\text {high }}$ satellite stem cells exist in a more stem cell-like state and are destined for self-renewal, whereas $M y f 5+$, PAX7low, and CD$34^{\text {low }}$ satellite progenitor cells are more committed and are therefore more "primed" for differentiation. Upon stimulation, quiescent satellite cells are activated and recruited to the cell cycle. Satellite stem cells subsequently undergo either symmetric or asymmetric cell division, generating 2 identical daughter

in response to injury [reviewed in Yin et al., 2013; Snijders et al., 2015]. Satellite cell activation is the process by which quiescent cells are recruited to the cell cycle. Following their activation, satellite cells commit to the myogenic program to participate in muscle tissue regeneration and repair [Relaix and Zammit, 2012]. Myogenesis is divided into the following steps (Fig. 1): upon stimulation, such as after injury or exercise, activated satellite cells undergo commitment to become myogenic progenitors [Yin et al., 2013]. These cells transition into myoblasts that undergo rapid proliferation and propagation, and finally differentiation [Yin et al., 2013]. Myoblasts may either fuse to pre-existing muscle fibers to donate a nucleus to a myotube, or fuse with each other to form new myotubes [Petrany and Millay, 2019].

Satellite cell commitment to myogenesis is dependent on the transcription factor PAX7 and myogenic regulatory factors (MRFs), including MYOD, MYF5, MRF4, and myogenin [Seale et al., 2000; Hernández-Hernández et al., 2017]. While MYOD is expressed by proliferating satellite cells, the upregulation of myogenin expression satellite stem cells for self-renewal or 1 satellite stem cell and 1 committed myogenic progenitor cell, respectively. These "primed" myogenic progenitors upregulate the expression of MYF5, indicating commitment to the myogenic program. Subsequently, myogenic progenitors proliferate, becoming myoblasts and expressing MYOD. Myoblasts may then fuse to either pre-existing muscle fibers to donate a nucleus to a myotube or differentiate and fuse with each other to form new myotubes. Expression of myogenin and MRF4, together with the downregulation of PAX7 expression in myocytes and myotubes mark terminal differentiation.

marks differentiation [Cornelison and Wold, 1997; Cooper et al., 1999]. Chromatin immunoprecipitation sequencing (ChIP-seq) analyses have revealed the biological role of PAX7 as a transcription factor involved in the binding of DNA motifs of a large catalog of genes that overall regulate myogenic identity, increase proliferation, and inhibit differentiation [Soleimani et al., 2012]. Thus, PAX7-mediated transcriptional activation of myogenic genes is a prerequisite for downstream differentiation and, consequently, regenerative myogenesis and muscle function throughout adulthood [Zammit et al., 2006; Relaix and Zammit, 2012]. During differentiation, the expression of PAX7 is downregulated while the expression of MRFs is upregulated [Olguin et al., 2007]. Satellite cells are therefore characterized by the distinct expression of PAX7 and the lack of MRF expression, while myogenic progenitors are described as PAX7-low and MRF-high [Cornelison and Wold, 1997; Seale et al., 2000].

The quiescent satellite cell population within adult muscle exists as a heterogeneous pool wherein some cells exist in a more committed state and others in a stem-like 
state [Biressi and Rando, 2010; Tierney and Sacco, 2016; Dell et al., 2019; Barruet et al., 2020; De Micheli et al., 2020; Kimmel et al., 2020; Xi et al., 2020] (Fig. 1). Satellite stem cells are a slow-dividing subset of the satellite cell pool which have never transcribed Myf5 and thus are termed Myf5- [Kuang et al., 2007]. Upon activation, these Myf5- satellite stem cells undergo either symmetric or asymmetric cell division, generating 2 identical daughter Myf5- satellite stem cells (symmetric expansion and selfrenewal) or $1 M y f 5$ - cell and 1 committed Myf5+ cell (asymmetric commitment), respectively [Kuang et al., 2007]. Through examination of isolated single myofibers from mice cultured ex vivo, it was shown that symmetric cell divisions occur in a planar orientation with respect to the muscle fiber, while asymmetric cell divisions occur in an apical basal orientation [Kuang et al., 2007]. Of note, intravital imaging analyses in regenerating muscles in live mice show that the majority of divisions occur bidirectionally along a "ghost fiber" which governs satellite cell behavior, while in toto imaging studies in zebrafish have found that asymmetric muscle stem cell divisions occur in a randomized orientation [Gurevich et al., 2016; Webster et al., 2016].

In addition to differential Myf5 expression, satellite cells can be sorted by their expression of PAX7 [Rocheteau et al., 2012]. Satellite cells with high PAX7 levels have low metabolic states and are less primed for differentiation, as the first cycle of mitosis subsequent to activation takes a longer period of time in comparison to satellite cells with lower PAX7 levels [Rocheteau et al., 2012]. Similarly, quiescent satellite cells expressing low levels of CD34 are more committed than those with high levels of CD34 [Garcia-Prat et al., 2020]. Thus, the long-term regenerative capacity of skeletal muscle is dependent on a heterogenous population of satellite cells consisting of satellite stem cells and committed progenitor cells, with distinct functional roles and varied cell fate potential for self-renewal and commitment to differentiation [Biressi and Rando, 2010; Tierney and Sacco, 2016]. Importantly, perturbations in the balance between satellite stem cell self-renewal and commitment has deleterious effects on muscle health and is an underlying cause of muscle degeneration [Chang et al., 2016]. The focus of this report is to review literature regarding satellite cell dysfunction in Duchenne muscular dystrophy (DMD), to provide context for a DMD therapeutic strategy which targets stem cell restoration, and finally to explore parallel perspectives of stem cell dysfunction in related musculoskeletal diseases.

Satellite Cell Contribution in DMD

\section{Evidence for Stem Cell Dysfunction in DMD}

DMD is a lethal X-linked recessive neuromuscular disorder characterized by a progressive deterioration of skeletal muscle [Emery et al., 2015]. Its underlying genetic cause is a mutation in the $D M D$ gene, giving rise to an absent or low-functioning, truncated, and unstable dystrophin protein [Hoffman et al., 1987]. The DMD gene is the longest mRNA in humans and is therefore highly susceptible to mutations [Koenig et al., 1987]. Indeed, over 7,000 mutations have been identified as indicated by the TREAT-NMD DMD Global Database [Bladen et al., 2015]. When translated, dystrophin is a rod-shaped protein that resides in the cell membrane [Koenig et al., 1988]. In healthy muscle, the protein is found along the entire length of the myofiber situated on the intracellular side where it assembles with components of the dystrophin-associated glycoprotein complex (DGC), which includes dystroglycan (DAG1), sarcoglycan and neuronal nitric oxide synthase (NOS-I) [Campbell and Kahl, 1989; Ervasti et al., 1990]. DMD-causing mutations of the DMD gene ultimately lead to disruption of the DGC and cause membrane instability, thereby resulting in enhanced susceptibility to myofiber damage from mechanical stress and fiber necrosis [Ervasti et al., 1990; Petrof et al., 1993]. Dystrophin-deficiency also alters membrane permeability, leading to higher intracellular calcium concentrations, which activates proteases (calpains) and delocalizes NOS from the subsarcolemmal membrane, which may contribute to further damage [Bodensteiner and Engel, 1978; Fong et al., 1990; Alderton and Steinhardt, 2000].

As satellite cells are the essential effectors of muscle regeneration, an unresolved question in the field remains: how are satellite cells impacted by dystrophin-deficiency and how do satellite cells contribute to DMD pathology? One initial hypothesis proposed is the satellite cell exhaustion model, whereby repetitive cycles of degeneration and regeneration cause the constitutive activation of satellite cells due to the enhanced demand for muscle repair, which results in progressive loss of stem cell regenerative capacity [Heslop et al., 2000; Sacco et al., 2010]. In conflict with this model, muscle fibers from DMD patients and myofibers isolated from $m d x$ mice, a well-established DMD mouse model harboring a naturally occurring nonsense mutation in the DMD gene, display elevated numbers of satellite cells [Bulfield et al., 1984; Maier and Bornemann, 1999; Kottlors and Kirschner, 2010; Bankole et al., 2013]. Thus, an emerging model in the field indicates that satellite cells in DMD are not simply being "exhausted"; rather, dystrophic satellite cells are

Cells Tissues Organs 2022;211:641-654 DOI: 10.1159/000514305 


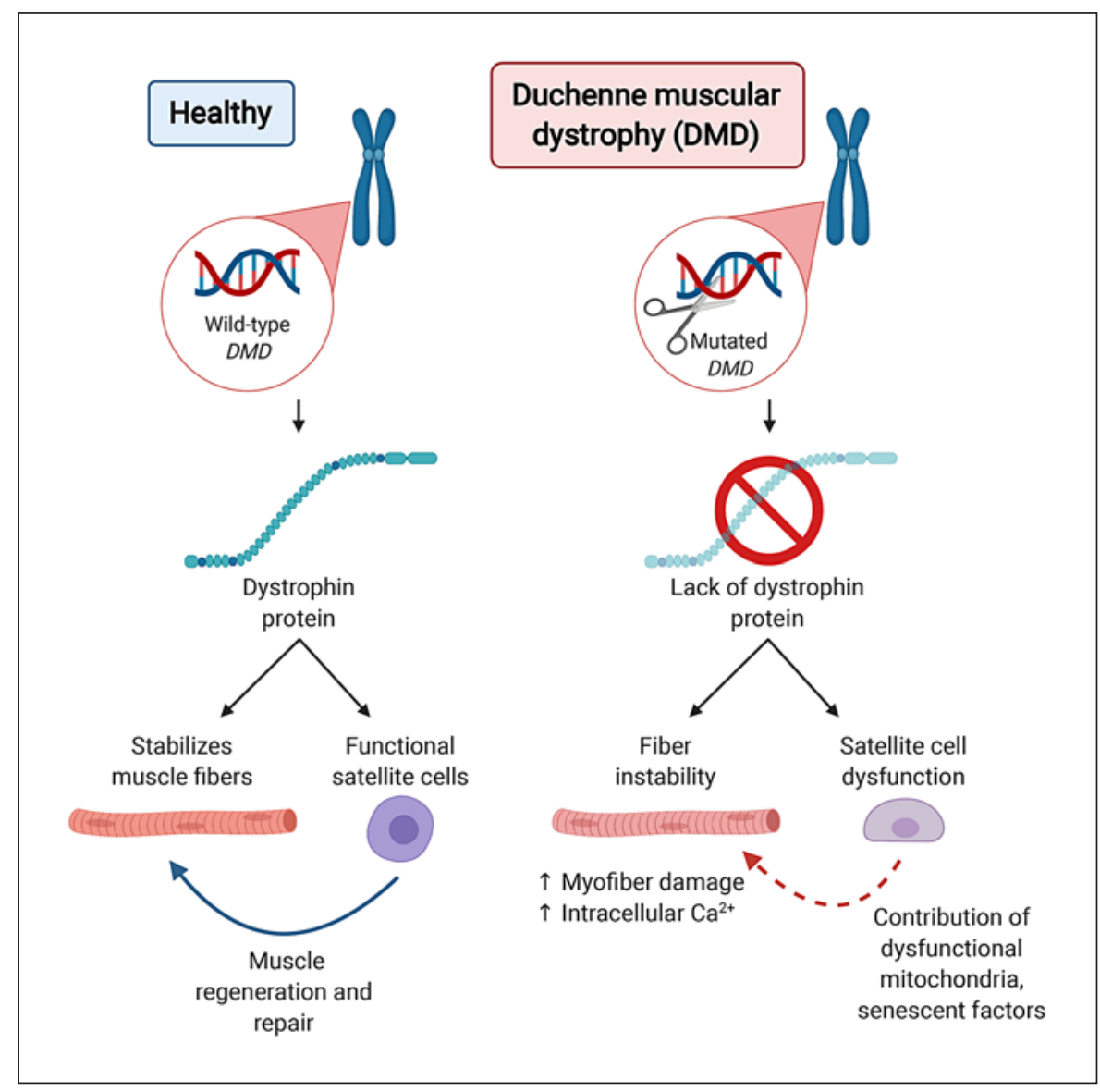

Fig. 2. Duchenne muscular dystrophy is a 2-pronged disease. Duchenne muscular dystrophy (DMD) is a progressive X-linked neuromuscular disorder caused by mutations in the DMD gene, encoding for dystrophin protein. In wild-type cells, dystrophin acts to stabilize muscle fibers during contractions. Conversely, in $\mathrm{DMD}$, the muscle fiber is weakened due to the absence of dystrophin, evidenced by membrane instability, myofiber damage, and increased intracellular calcium concentrations. Furthermore, sat- ellite cells also express dystrophin. Recent evidence has shown that dystrophin-deficient DMD satellite cells are dysregulated; exhibiting reduced regenerative capacity, impaired asymmetric cell division, decreased myogenic commitment, altered differentiation kinetics, signs of mitotic stress, and enhanced entry to senescence. DMD can therefore be described as a 2-pronged disease, as dystrophin loss in both muscle fibers and satellite cells contribute to the disease phenotype. dysfunctional and unable to contribute efficiently to muscle repair. Several recent reports have supported this model of satellite cell dysfunction, including studies indicating that $m d x$ satellite cells exhibit impaired asymmetric cell division, reduced myogenic commitment, altered differentiation kinetics, signs of mitotic stress, and enhanced susceptibility to enter senescence [reviewed in Chang et al., 2016]. A critical recent discovery is that satellite cells themselves express dystrophin, an observation made in satellite cells derived from both human and mouse, thus indicating that dystrophin has satellite cellspecific functions [Dumont et al., 2015; Alexander et al., 2016]. It is thus reasonable that satellite cell dysfunction is a contributing mechanism toward the DMD disease phenotype [Chang et al., 2016]. DMD can therefore be described as a 2-pronged disease, wherein dystrophin deficiency-mediated satellite cell dysfunction exacerbates the disease phenotype alongside the weakening of the muscle fiber membrane (Fig. 2). This section reviews various aspects of stem cell dysfunction in DMD, as summarized in Figure 3.

\section{Impaired Asymmetric Division}

In addition to maintenance of sarcolemmal integrity, dystrophin also plays a crucial role in establishing satellite cell polarity [Dumont et al., 2015]. MAP/microtubule af- 


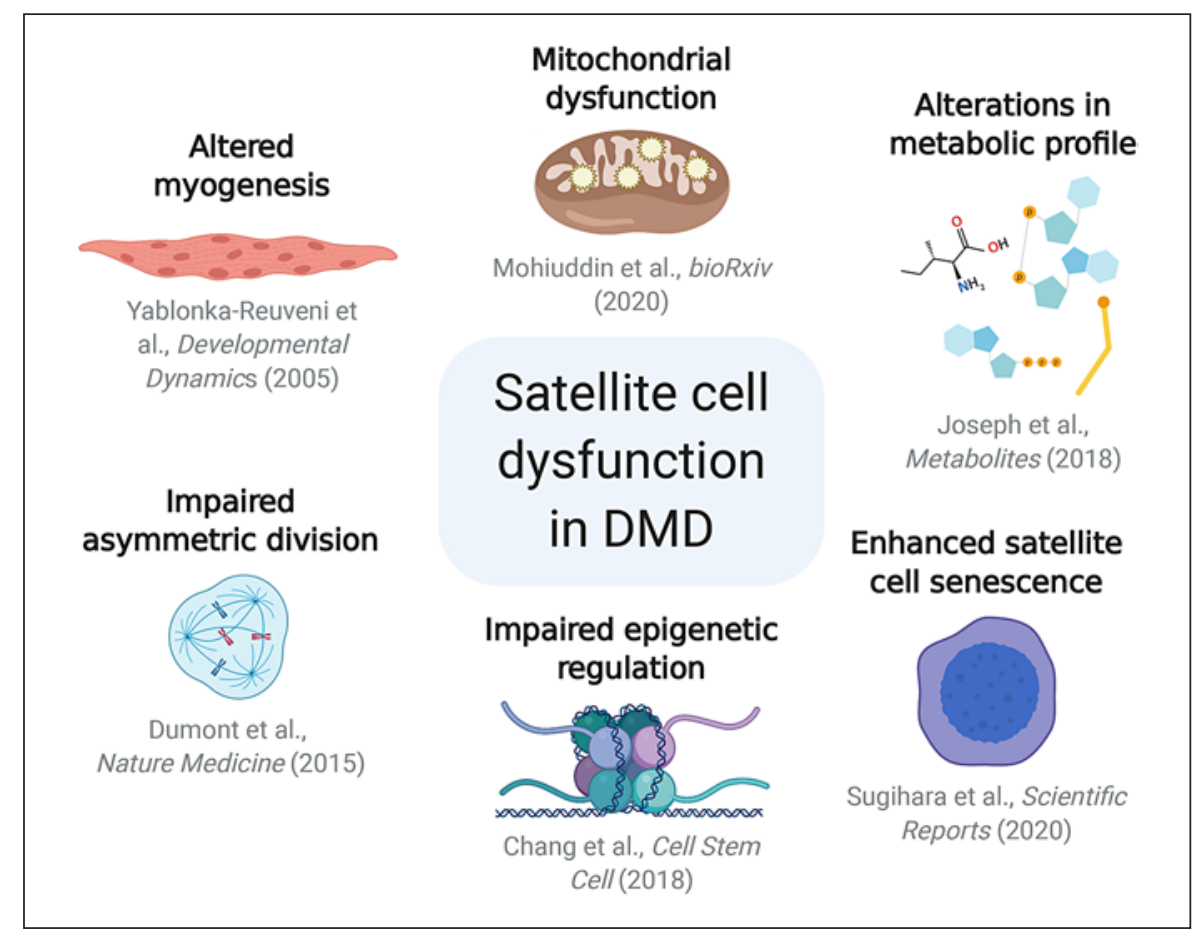

Fig. 3. Satellite cell dysfunction in Duchenne muscular dystrophy (DMD). The absence of dystrophin protein in satellite cells leads to a variety of satellite cell dysfunctions. Asymmetric cell division is impaired due to impaired protein interactions between dystrophin and a polarity-influencing protein, MARK2. Loss of dystrophin glycoprotein complex (DGC)-mediated regulation of CARM1, an epigenetic activator of myogenic genes, results in altered epigenetic activation of Myf5 during satellite cell commitment. Myogenic differentiation of dystrophic satellite cells is accelerated in comparison to wild-type due to a rapid decline in

finity-regulating kinase 2 (MARK2, also known as Par1b) is a well-conserved Ser/Thr kinase and an essential cell polarity regulator [Wu and Griffin, 2017]. Dumont et al. [2015] showed that, in a subset of activated satellite cells, dystrophin is expressed at high levels and binds to MARK2. Furthermore, the DGC member DAG1 also interacts with MARK2.

Studies in Drosophila have shown that phosphorylation of Par3 by Par1, the Drosophila homolog of MARK2, results in asymmetric distribution of the PAR complex, a well-conserved protein complex (consisting of Par3/ Par6/aPKC) that plays critical roles in cell polarity establishment and maintenance [McCaffrey and Macara, 2012]. Par1 mediates asymmetric divisions in zygotes of Caenorhabditis elegans and controls microtubule dynamics in mammalian neurons [Wu and Griffin, 2017]. In satellite stem cells, the PAR complex regulates stem cell
MYOD expression paired with premature expression of myogenin. The metabolic profile of dystrophic satellite cells is altered, demonstrated by enhanced accumulation of long chain acylcarnitine species. Dystrophin-deficient satellite cells also exhibit increased levels of oxidative stress and are more prone to senescence. Moreover, augmented oxidative stress in DMD satellite cells induces mitochondria dysfunction. Consequently, bioenergetically impaired mitochondria are transferred to DMD muscle tissue during myoblast fusion, thus worsening skeletal muscle function. polarity as knockdown of the mammalian Par3 homologue, PARD3, results in the loss of asymmetric divisions and reduced regenerative capacity [Troy et al., 2012; Dumont et al., 2015].

Together with DAG1, dystrophin forms a scaffold to which MARK2 binds [Dumont et al., 2015]. This interaction mediates the direct phosphorylation of PARD3, leading to the asymmetric distribution of the PAR complex [Dumont et al., 2015]. In dystrophic contexts, expression of MARK2 is diminished, and the PARD3-containing PAR complex remains uniformly distributed, thus resulting in a reduction in asymmetric cell divisions in dystrophin-deficient satellite cells [Dumont et al., 2015]. Therefore, dystrophin establishes cell polarity in satellite cells and is critical in ensuring proper asymmetric satellite stem cell divisions [Dumont et al., 2015]. 


\section{Impaired Epigenetic Regulation of Myogenic Gene} Expression

When Myf5- satellite stem cells undergo asymmetric cell division, they give rise to one $M y f 5$ - daughter stem cell and one committed Myf5+ daughter cell [Kuang et al., 2007]. In order to transcriptionally activate $M y f 5$ expression, PAX7 is first methylated at several arginine residues by CARM1, an arginine methyltransferase [Kawabe et al., 2012]. PAX7 subsequently recruits the ASH2L:MLL1/2:WDR5:RBBP5 histone H3 lysine 4 (H3K4) methyltransferase complex to the proximal promoter of $M y f 5$, leading to its permissive tri-methylation on H3K4 (H3K4me3), a chromatin modification marking active transcription in eukaryotes [McKinnell et al., 2008; Benayoun et al., 2014].

Recently, the mitogen-activated protein kinase (MAPK) p38 $\gamma /$ MAPK12 was identified as a regulatory kinase of CARM1 and thus controls CARM1 functions during satellite stem cell division [Chang et al., 2018]. Amongst the p38 MAP kinase family, p38 $\gamma$ is unique in its ability to directly phosphorylate CARM1 on Ser 572 [Chang et al., 2018]. Phosphorylation of CARM1 at this site prevents the nuclear translocation of the CARM1 $\triangle \mathrm{E} 15$ isoform, which is the isoform responsible for methylating PAX7. Thus, the methylation of PAX7 by CARM1 is negatively regulated by p38 $\gamma$ [Chang et al., 2018]. Additionally, p38 $\gamma /$ CARM1 interacts with the DGC via a direct interaction with $\beta 1$-syntrophin protein in satellite cells [Chang et al., 2018]. During asymmetric cell division, $\mathrm{p} 38 \gamma$ localization is basally restricted by $\beta 1$ syntrophin to allow for the phosphorylation of CARM1 and the subsequent inhibition of $M y f 5$ activation [Chang et al., 2018]. These findings demonstrate that $\mathrm{p} 38 \gamma$ negatively regulates asymmetric cell divisions but is required for symmetric self-renewal, wherein Myf5 transcription remains epigenetically repressed [Chang et al., 2018].

In the muscles of $m d x$ mice, enhanced levels of miRNA-222 (miR-222) results in the reduced expression of $\beta 1$-syntrophin compared to wild-type [De Arcangelis et al., 2010]. Proximity ligation assays revealed a complete lack of interaction between p38 $\gamma$ and $\beta 1$-syntrophin in $m d x$ mice in correlation with enhanced CARM1 phosphorylation and decreased CARM1/PAX7 interactions [Chang et al., 2018]. Further, Myf5 exhibited significantly reduced levels of $\mathrm{H} 3 \mathrm{~K} 4 \mathrm{me} 3$ at its transcriptional start site in $m d x$ satellite cells [Chang et al., 2018]. Overall, this indicates that $\mathrm{p} 38 \gamma$ regulation of CARM1 is perturbed in $m d x$ satellite cells, leading to impaired epigenetic activation of $M y f 5$, a key myogenic commitment gene, during satellite cell division [Chang et al., 2018].

\section{Altered Myogenesis}

Satellite cells isolated from $m d x$ and wild-type mice exhibit distinct differentiation properties and kinetics [Yablonka-Reuveni and Anderson, 2006]. Dystrophic myoblasts in culture differentiate more rapidly compared to wild-type cells and exhibit an earlier decline in MYOD expression paired with an upregulation of myogenin expression [Yablonka-Reuveni and Anderson, 2006]. In addition to myogenic regulatory factors, expression of the myocyte enhancer factor 2 (MEF2) family of transcription factors (including MEF2A through D), which contribute toward myogenesis, is also upregulated in differentiating satellite cells leading to the enhanced expression of muscle structural genes [Naya and Olson, 1999; Yablonka-Reuveni and Anderson, 2006]. $M d x$ primary myoblast cell cultures also display early MEF2A expression and myotube formation [Yablonka-Reuveni and Anderson, 2006]. Overall, the differentiation of $m d x$ satellite cells is accelerated in comparison to wild-type [Yablonka-Reuveni and Anderson, 2006]. Furthermore, $m d x$ muscle fibers exhibit an increased incidence of muscle fiber branching, a weakened fiber composed of 2 or more cytoplasmically continuous strands, in comparison to wild-type fibers, an observation that has been characterized both in vitro and in vivo [Chan and Head, 2011; Faber et al., 2014; Chal et al., 2015]. Thus, the enhanced vulnerability of myofibers to contractile damage, may be due to the presence of branched fibers [Chan and Head, 2011]. Based on these observations of defective myogenesis, it is evident that the observed muscle degeneration in DMD is influenced by muscle tissue-independent or satellite/myogenic cell-autonomous factors.

\section{Mitochondrial Dysfunction}

During the muscle regeneration process, differentiating satellite cells can either fuse to pre-existing muscle fibers or form myofibers de novo [Petrany and Millay, 2019]. Since myofibers are post-mitotic and multi-nucleated, the intracellular mitochondrial network is tightly regulated to ensure mitochondrial-nuclear genome communication, mitochondrial homeostasis, and bioenergetic function [Romanello and Sandri, 2016; Hood et al., 2019]. Maintenance of mitochondrial health involves the degradation of damaged mitochondria through mitophagy and the acquisition of new mitochondria from satellite cells upon their fusion with myofibers [Mohiuddin et al., 2020]. Moreover, mitochondria are dynamic organelles and constantly undergo fusion and fission to regulate their size, shape, and volume to adapt to the bioenergetic needs of the cell [Ryan and Hoogenraad, 2007; Casuso and Huertas, 2020]. 
Mitochondrial dysfunction is one of the earliest cellular deficits exhibited by $m d x$ muscle [Scholte and Busch, 1980; Vila et al., 2017; Hughes et al., 2019]. The absence of dystrophin in muscle fibers results in increased cytosolic calcium concentrations, oxidative stress, and cell death [Rando et al., 1998; Allen et al., 2016]. This creates a pro-inflammatory environment leading to mitochondrial dysfunction, as well as enhanced $\mathrm{H}_{2} \mathrm{O}_{2}$ emissions due to impaired oxidative phosphorylation from the mitochondria of $m d x$ mice [Hughes et al., 2019]. Altered mitochondrial dynamics were also observed in utrophindystrophin deficient (DKO) mice, which were generated by deleting the gene encoding the dystrophin homologue utrophin in $m d x$ mice, thereby creating a pathologically more severe DMD mouse model [Deconinck AE et al., 1997; Pant et al., 2015].

In a recent study, Mohiuddin et al. [2020] showed that satellite cells play a role in ensuring myofiber mitochondrial homeostasis. Moreover, active mitochondria are required for the repair of sarcolemmal injury [Sharma et al., 2012]. Thus, when DMD-afflicted satellite cells transfer their mitochondria to myofibers, they donate bio-energetically impaired mitochondria and augment the preexisting mitochondrial dysfunction within the muscle tissue [Mohiuddin et al., 2020].

\section{Alterations in Metabolic Profile}

The mitochondrial network is considered the electrical power grid of the cell and directly impacts the cellular metabolic state. Indeed, the mitochondrial impairment observed in DMD muscle is accompanied by an increase in energy demand [Pant et al., 2015]. To compensate, an upregulation of glucose metabolism-related enzymes, including hexokinase 1 and pyruvate kinase M2, was demonstrated in utrophin/dystrophin DKO tissue homogenates [Pant et al., 2015]. Thus, the mitochondrial dysfunction observed in dystrophic muscles may explain the impaired oxidative phosphorylation and increased reliance on glycolysis [Pant et al., 2015]. Similarly, $m d x$ myoblasts exhibit higher rates of lactate formation [Onopiuk et al., 2009].

Within satellite cells, alterations in the fatty acid metabolic profile have been observed [Joseph et al., 2018]. Joseph et al. performed non-targeted metabolomic analysis in satellite cells and serum isolated from $m d x$ mice and found extensive metabolic dysregulation [Joseph et al., 2018]. An accumulation of long chain acylcarnitine species, notably elaidic carnitine (C18), linoleyl carnitine (C18), palmitoyl-L-carnitine (C16), and DL-stearoylcarnitine, provided evidence for fatty acid metabolism de- fects and an overall reduction in fatty acid oxidation capacity [Joseph et al., 2018]. Such accumulations have been shown to provoke cell stress in myotubes and affect differentiation kinetics [McCoin et al., 2015; Joseph et al., 2018; Xu et al., 2018]. Moreover, acylcarnitine accumulation was also observed in adipose progenitor cells [Joseph et al., 2018]. Thus, the metabolic dysfunction is widespread in dystrophic mice and affects cell types outside of skeletal muscle [Joseph et al., 2018]. Cellular metabolism is emerging as an important regulator of stem cell fates and functions, thus, alterations in the metabolic status of DMD satellite cells may impact their regenerative capacity [Wanet et al., 2015].

\section{Enhanced Satellite Cell Senescence}

Cellular senescence is the induction of irreversible cell cycle arrest in response to a variety of stimuli, including DNA damage and oxidative stress, as a means to prevent the propagation of potentially harmful and/or damaged cells [Campisi, 2013]. In DMD, the lack of dystrophin causes a sustained leakage of cell cytoplasm into the extracellular milieu which triggers immune responses involving inflammatory cell infiltration and cytokine secretion [Rosenberg et al., 2015]. This results in increased levels of oxidative stress, ultimately leading to satellite cell senescence [Petrillo et al., 2017; Sugihara et al., 2020]. The presence of senescence markers in dystrophin-deficient satellite cells have been detected in satellite cells from DMD mouse and rat models [Zhang et al., 2016; Sugihara et al., 2020]. Once satellite cells enter a pre-senescent state, they lose their ability to transition between quiescence and activated states and instead are irreversibly fated toward cellular senescence [Sousa-Victor et al., 2014]. The accumulation of senescent satellite cells subsequently results in a decrease in self-renewal and reduced generation of myogenic progenitors within the satellite cell pool following muscle regeneration [Sousa-Victor et al., 2014; Sugihara et al., 2020]. Thus, satellite cell senescence causes an impairment in stem cell regenerative capacity and inhibits the myogenic program [Sousa-Victor et al., 2014; Latella et al., 2017; Sugihara et al., 2020]. Over time, this causes a decline in satellite cell numbers and greatly affects the ability of muscle to regenerate, as observed during aging [Sousa-Victor et al., 2014; Garcia-Prat et al., 2020; Sugihara et al., 2020].

While the exact role of mitochondria in senescence remains under investigation, mitochondrial dysfunction serves as a biomarker for cell senescence [Chapman et al., 2019]. Aging-induced dysfunctional mitochondria are often a result of oxidized nicotinamide adenine dinucleo- 
tide (NAD+) depletion, likely a consequence of stem cells' reliance on glycolysis for energy which reduces NAD+ levels [Zhang et al., 2016]. Intriguingly, NAD+ repletion using precursors such as nicotinamide riboside have been shown to improve satellite cell function: resulting in increased satellite cell numbers in both young and old mice and improving muscle function and regeneration in aged mice [Zhang et al., 2016].

\section{Restoring Stem Cell Function as a Therapeutic Strategy for DMD}

DMD is the most common muscular dystrophy in children, with 15.9 and 19.5 cases per 100,000 live male births in the USA and UK, respectively [Ryder et al., 2017]. Given the lack of clinical symptoms present at birth, the earliest signs of motor development delays are detected around 2-2.5 years of age, and diagnosis typically occurs around age 4 [Falzarano et al., 2015]. As the disease advances, progressive degeneration causes rapid accumulation of muscle damage and worsening of disease severity, resulting in motor delays, respiratory impairment, and cardiomyopathy [Emery et al., 2015]. Ultimately, DMD is fatal and results in the loss of life of DMD patients in their late teens to early twenties from cardiorespiratory difficulties [Emery et al., 2015].

DMD therapeutics currently aim toward improving patient care, hoping to extend survival and enhance quality of life, by targeting all muscles in the body [Birnkrant et al., 2018; Salmaninejad et al., 2018]. Corticosteroids, such as prednisolone, are the only drugs presently effective in DMD and are usually offered to all patients to prolong survival [Manzur et al., 2008]. Their mechanism of action in DMD is yet to be elucidated, but they potentially alter the expression of a variety of genes in muscle fibers, lower cytosolic calcium concentrations, and/or slow the rate of muscle breakdown [Khan, 1993; Muntoni et al., 2002]. However, long-term usage of corticosteroids leads to negative side effects including weight gain, risk for hypertension, and loss of bone density [Bushby et al., 2010]. Thus, although corticosteroids are relatively well-tolerated, a curing and long-term treatment for DMD has yet to be discovered.

Importantly, despite recent evidence that satellite cells directly contribute to the disease phenotype observed in DMD, current therapies do not take satellite cells into account [Chang et al., 2016]. Gene delivery by adeno-associated vectors (AAVs) and exon skipping with antisense oligonucleotide (AON), currently in Phase I/II clinical trials, are 2 genetic approaches that serve to reinstate dystrophin expression and hold promise as DMD treatments [Blankinship et al., 2004; Gregorevic et al., 2004; Bowles et al., 2012; Koo and Wood, 2013; Gao et al., 2019]. However, while both AAVs and AONs can effectively target muscle tissue, they are limited due to poor uptake by satellite cells [Arnett et al., 2014; Chang et al., 2016]. Moreover, given that dystrophin is the longest mRNA in humans, DMD-targeting AAVs are restricted by the size of the packaging vector. In therapies that deliver a truncated $D M D$ transcript, these forms of micro-dystrophin lack the spectrin-like repeats that are critical for mediating the interaction between dystrophin and MARK2, which regulates the establishment of cell polarity [Yamashita et al., 2010; Duan, 2018]. Thus, using AAVs that deliver microdystrophin would not ameliorate satellite cell dysfunctions relating to asymmetric cell division. Additionally, utrophin upregulation has been examined as a potential method to compensate for the lack of dystrophin function [Tinsley et al., 1996, 1998; Deconinck N et al., 1997; Miura and Jasmin, 2006]. This can be accomplished by several methods: administration of L-arginine, a substrate of NOS-I within the DGC; administration of heregulin, a nerve-derived-trophic factor; increasing calcineurin-NFAT signaling; or stimulating internal ribosome entry site-dependent translation of utrophin through eEF1A2 [Khurana et al., 1999; Chakkalakal et al., 2003; Barton et al., 2005; Peladeau et al., 2020]. However, utrophin does not interact with MARK2 and its expression would not be predicted to restore asymmetric cell divisions in satellite cells [Yamashita et al., 2010].

Certain studies have indicated that targeting satellite cells can have therapeutic benefits for DMD. One potential method to increase asymmetric cell divisions is to stimulate an alternative cell polarity pathway through the epidermal growth factor receptor (EGFR) [Wang et al., 2019]. Treatment with EGF, the ligand for EGFR, has been shown to activate Aurora kinase A to orient mitotic centrosomes and restore cell polarity [Wang et al., 2019]. Indeed, EGF treatment in $m d x$ mice was effective in enhancing asymmetric divisions of dystrophic satellite cells and was accompanied by improved regeneration and muscle strength [Wang et al., 2019]. In another study, Nance et al. [2019] successfully performed gene editing in satellite cells using CRISPR and adeno-associated virus serotype-9 (AAV9) and restored dystrophin expression in $m d x$ satellite cells.

A variety of approaches have been explored to specifically target stem cell dysfunctions in DMD. For example, glycine supplementation in $m d x$ mice has been demon- 
strated to increase DMD satellite proliferation by activating the mammalian target of rapamycin complex 1 (mTORC1) and enhance transplantation efficiency of exogenous satellite cells in dystrophic muscles [Lin et al., 2020]. Given the NAD+ deficiency observed in $m d x$ mitochondria, treatment with nicotinamide riboside, the $\mathrm{NAD}+$ precursor, improved satellite cell function in $m d x$ mice [Zhang et al., 2016]. Furthermore, nicotinamide riboside-treated satellite cells are more effective at replenishing the satellite cell pool following transplantation into $m d x$ mice [Zhang et al., 2016].

Intriguingly, one recent study has found that satellite cell depletion in dystrophic mice during early adulthood is beneficial, suggesting that dystrophic satellite cells play a deleterious role in DMD phenotypes. Dystrophic mice lacking satellite cells as of 8 weeks of age both escaped muscle degeneration and initiated a protective response against consequent muscle damage of pre-existing myofibers [Boyer et al., 2019]. This study suggests that by eliminating dysfunctional satellite cells, and perhaps the contribution of dysfunctional mitochondria and deleterious senescent factors, the phenotype of DMD muscles are improved. Intriguingly, the use of the senolytic drug ABT263, which specifically depletes senescent cells, in $m d x$ mice also improved the muscle regenerative capacity of $m d x$ mice and reduced the expression of senescence markers [Sugihara et al., 2020].

An alternative study examined the restoration of satellite cell function by improving the microenvironment through parabiotic pairing of wild-type and $m d x$ mice [Lu et al., 2020]. When green fluorescent protein (GFP)expressing wild-type and non-GFP-expressing $m d x$ mice are surgically joined, the dystrophic phenotype of $m d x$ mice was improved, including decreased inflammation, necrosis, and macrophage infiltration [Lu et al., 2020]. While few GFP-expressing cells were found in the muscle tissue of $m d x$ mice, $m d x$-isolated GFP-expressing cells were capable of undergoing myogenic differentiation in vitro and co-expressed mesenchymal stem cell and macrophage markers [Lu et al., 2020]. Interestingly, macrophages are required to maintain satellite cell fate as macrophage depletion in $m d x$ mice shifts satellite cell identity towards adipogenic differentiation, thereby exacerbating the DMD phenotype, reducing the total number of satellite cells and causing fat deposition and fibrosis [Madaro et al., 2019]. Thus, several lines of evidence in the literature support the notion that restoring satellite cell function holds great therapeutic promise and must be taken into consideration in future putative DMD treatments.

Satellite Cell Contribution in DMD

\section{Stem Cell Contribution in Other Muscle Diseases and Parallels to DMD}

\section{Muscle Cancer}

In human cancers related to myogenic differentiation, dystrophin has been identified as a tumor supressor as it inhibits myogenic sarcoma cell migration and invasion [Wang et al., 2014]. One such cancer is rhabdomyosarcoma (RMS), a rare and aggressive soft tissue sarcoma whose development is influenced by DMD [Boscolo Sesillo et al., 2019]. By crossing $m d x / m T R$ mice, a DMD mouse model whose satellite cells possess telomeres which progressively shorten over time and exhibit worsened disease severity, together with $p 53 \mathrm{Het}$ tumor-inducing mice, Boscolo Sesillo et al. [2019] showed that dystrophic satellite cells caused an acceleration of RMS induction through both tumorsphere formation assays in vitro and RMS formation in vivo. Specifically, dystrophic satellite cells can give rise to RMS [Boscolo Sesillo et al., 2019]. Prior to tumor formation, satellite cells isolated from the triple knockout p53KO:mdx/mTR mice exhibited enhanced self-renewal, DNA damage, and expressed an RMS-characteristic genetic signature [Boscolo Sesillo et al., 2019]. Additionally, C-C motif chemokine ligand 11 (Ccl111), a chemokine responsible for immune cell recruitment during inflammation, and regulator of $G$ protein signaling 5 (Rgs5), whose overexpression inhibits the sonic hedgehog signaling pathway, are both downregulated in RMS-afflicted satellite cells [Mahoney et al., 2013; Kindstedt et al., 2017; Boscolo Sesillo et al., 2019]. Upon rescue of their expression in satellite cells, tumorsphere size decreases, indicating that their differential expression in satellite cells contributes to the formation of RMS [Boscolo Sesillo et al., 2019]. Intriguingly, Van Gogh-like 2 (Vangl2), a regulator of the non-canonical Wnt/planar cell polarity pathway that drives symmetric satellite stem cell divisions, is highly expressed in RMS progenitor-like cells, thereby promoting satellite cell self-renewal and is required for xenograft growth of human RMS in mice [Le Grand et al., 2009; Hayes et al., 2018]. Vangl2 leads to downstream activation of the small GTPase RhoA, which influences cell polarity [Phillips et al., 2005]. Thus, impairments in stem cell self-renewal and cell polarity, as is the case in DMD, may create environments that are conducive to tumorigenesis, as evidenced in RMS [Boscolo Sesillo et al., 2019]. Indeed, $m d x$ mice are more susceptible to developing spontaneous RMS [Chamberlain et al., 2007]

Cells Tissues Organs 2022;211:641-654

DOI: $10.1159 / 000514305$ 


\section{Cachexia}

Cancer-induced cachexia is a multifactorial metabolic syndrome involving the severe loss of skeletal muscle mass and adipose tissue and is responsible for $~ 22 \%$ of cancer-related deaths [Tisdale, 2009; Fearon et al., 2011]. It is mediated by various cytokines, such as interferon $\gamma$ and tumor necrosis factor $\alpha$, which stimulate the activity of transcription factors STAT3 and NF- $\kappa \mathrm{B}$ concurrent with an increase in inducible NOS and interleukin-6 expression [Strassmann et al., 1992; Williams et al., 1994; Guttridge et al., 2000; Di Marco et al., 2005; Ma et al., 2017; Cramer et al., 2018]. Similar to DMD, the DGC plays a contributing role in cachexia [Acharyya et al., 2005]. Dystrophin levels are reduced due to circulating cachexic factors, leading to myofiber membrane damage in developing tumors which may cause muscular atrophy [Acharyya et al., 2005]. Accompanying the reduction in dystrophin protein, $\beta$-dystroglycan and $\beta$-sarcoglycan of tumor cachexia mouse models and cachectic patients are aberrantly glycosylated in manners similar to those in $m d x$ mice, thus furthering DGC dysfunction [Acharyya et al., 2005]. Satellite cells of tumor-bearing colon-26 mice (a mouse model of colon carcinoma) also exhibit reduced myogenic capacity in vivo, as proliferation and differentiation were severely impaired [Inaba et al., 2018]. Specifically, the muscle damage induced by circulating tumorigenic factors cannot be repaired as myogenic differentiation is stalled and satellite cell fusion is impaired [He et al., 2013]. Moreover, due to cachexia-induced NF$\kappa \mathrm{B}$ activation, PAX7 expression is dysregulated [He et al., 2013]. The expression of PAX7 is constitutively sustained in myogenic progenitor cells, preventing them from fully progressing through the myogenic program, thereby promoting muscular atrophy [He et al., 2013]. Similarly, NF$\kappa \mathrm{B}$ activation leads to a reduction in levels of $M y o D$ mRNA transcripts [Guttridge et al., 2000]. Thus, analogous to $\mathrm{DMD}$, an inability to effectively activate the myogenic program in satellite cells and myogenic progenitors contribute towards increased muscle wasting in cancerinduced cachexia.

\section{Sarcopenia}

Sarcopenia is the age-related loss of skeletal muscle mass and function [Doherty, 2003]. In parallel with the constant activation of satellite cells observed in $m d x$ mice, aged satellite cells, such as those of geriatric humans, fail to maintain G0-reversible quiescence and instead enter a G0-irreverisble senescent state in sarcopenic muscle, which results in a decline in their numbers and function [Heslop et al., 2000; Sousa-Victor et al., 2014]. This tran- sition toward a senescent state is prevented by basal levels of macroautophagy (hereby referred to as autophagy) of satellite cells as well as through the maintenance of an active organelle and protein homeostasis network [SousaVictor et al., 2014; García-Prat et al., 2016]. Aged satellite cells exhibit a loss of autophagy and consequently accumulate damaged proteins and organelles, which ultimately leads to satellite cell exhaustion and senescence [García-Prat et al., 2016]. Similarly, in $m d x$ mice, a progressive decline in autophagy is observed after an initial upregulation of autophagy during the early stages of DMD [Fiacco et al., 2016]. Interestingly, in vivo restoration of autophagy prevents aging-induced satellite cell senescence [García-Prat et al., 2016]. The regenerative decline observed in DMD is therefore reminiscent of the characteristics observed in aging.

Additionally, loss of dystrophin at the protein level but not at the mRNA level is associated with aging [Hughes et al., 2017]. This may be due to miR-31 (also known as a dystrophy-associated miRNA, dystromiR), which is known to target dystrophin mRNA and is found at 4- to 5 -fold higher levels in sarcopenic muscle [Hughes et al., 2017]. Consequently, in the absence of dystrophin, various myogenic proteins, such as $\alpha$-sarcoglycan, syntrophin, sarcospan, and laminin, are upregulated, which has a deleterious effect on membrane stability and promotes muscle damage [Hughes et al., 2017]. Thus, the enhanced susceptibility to muscle damage and increase in satellite cell senescence observed in DMD may represent a phenotype resembling premature aging.

\section{Conclusion}

In this literature review, we describe DMD as a 2-pronged disease; a disease affecting the muscle tissue as well as a muscle stem cell disease. Firstly, the absence of dystrophin in muscle tissue leads to impaired DGC formation and progressive weakening of the muscle fiber membrane [Petrof et al., 1993]. Dystrophic muscles are rendered highly susceptible to contraction-induced sarcolemmal injury in the absence of dystrophin, which provides mechanical reinforcement during muscle contraction [Petrof et al., 1993]. Consequent and eventual inflammation and fibrosis lead to loss of muscle mass and function [Kharraz et al., 2014]. The dystrophic and degenerative phenotype is exacerbated due to the dysfunction of satellite cells [Chang et al., 2016]. Satellite cells themselves also express dystrophin and exhibit a variety of dysfunctions as a result of dystrophin deficiency [Du- 
mont et al., 2015; Chang et al., 2016, 2018]. These stem cell dysfunctions include impaired epigenetic regulation of gene expression, reduced asymmetric cell division, accelerated differentiation, altered metabolism, increased susceptibility to senescence, and dysfunctional mitochondria [Yablonka-Reuveni and Anderson, 2006; Dumont et al., 2015; Chang et al., 2018; Joseph et al., 2018; Mohiuddin et al., 2020; Sugihara et al., 2020]. Current DMD therapeutic strategies do not account for the need to restore satellite cell function [Chang et al., 2016]. Recent literature shows promise for satellite cell targeted therapies, which serve to restore endogenous regenerative capacity within dystrophic muscles [Wang et al., 2019]. However, it is important to acknowledge that exclusively targeting satellite cells as a therapeutic strategy has limitations. Disrupting the balance between satellite cell symmetric and asymmetric cell divisions has longterm consequences on the efficiency of muscle regeneration and muscle health and longevity [Chang et al., 2016]. For example, excessive asymmetric cell division may result in stem cell depletion and exhaustion. Moreover, restoring asymmetric cell division without addressing other aspects of stem cell impairment may have negative effects following differentiation and fusion of these dystrophic satellite cells into the myofiber. These are critical considerations that will need to be addressed as the field moves forward.

Given the dual contribution of dystrophin in muscle tissue and satellite cells, it is imperative to consider stem cell restoration therapy in combination with the current approaches, such as AAV and AON-mediated gene therapy, to provide a combinatorial and synergistic strategy for treating and curing DMD. We anticipate that by re- storing endogenous satellite cell function to mitigate the various aspects of stem cell dysfunction (i.e., enhanced senescence, metabolic alterations, and mitochondrial dysfunction) alongside strategies to upregulate dystrophin expression within the myofiber will lead to a comprehensive and holistic approach for treating DMD. Finally, identified strategies that restore satellite stem cell function in DMD may also be applicable to other muscle diseases such as rhabdomyosarcoma, cachexia and sarcopenia.

\section{Acknowledgements}

R.L.F. is supported by a Maysie MacSporran Studentship from McGill University. Figures 1-3 were created with BioRender.com.

\section{Conflict of Interest Statement}

The authors declare no conflicts of interest.

\section{Funding Sources}

Work in the Chang laboratory is supported by research funds from the Innovation Research Program for Early Career Investigators from the Stem Cell Network.

\section{Author Contributions}

Conceptualization: R.L.F. and N.C.C. Writing: original draft, review and editing, R.L.F. and N.C.C. Funding Acquisition: N.C.C. Supervision: N.C.C.

\section{References}

Acharyya S, Butchbach ME, Sahenk Z, Wang H, Saji M, Carathers M, et al. Dystrophin glycoprotein complex dysfunction: a regulatory link between muscular dystrophy and cancer cachexia. Cancer Cell. 2005;8(5):421-32.

Alderton JM, Steinhardt RA. Calcium influx through calcium leak channels is responsible for the elevated levels of calcium-dependent proteolysis in dystrophic myotubes. J Biol Chem. 2000;275(13):9452-60.

Alexander MS, Rozkalne A, Colletta A, Spinazzola JM, Johnson S, Rahimov F, et al. CD82 Is a Marker for Prospective Isolation of Human Muscle Satellite Cells and Is Linked to Muscular Dystrophies. Cell Stem Cell. 2016;19(6): $800-7$.
Allen DG, Whitehead NP, Froehner SC. Absence of Dystrophin Disrupts Skeletal Muscle Signaling: Roles of $\mathrm{Ca} 2+$, Reactive Oxygen Species, and Nitric Oxide in the Development of Muscular Dystrophy. Physiol Rev. 2016;96(1):253-305.

Arnett AL, Konieczny P, Ramos JN, Hall J, Odom G, Yablonka-Reuveni Z, et al. Adeno-associated viral (AAV) vectors do not efficiently target muscle satellite cells. Mol Ther Methods Clin Dev. 2014;1:14038.

Bankole LC, Feasson L, Ponsot E, Kadi F. Fibre type-specific satellite cell content in two models of muscle disease. Histopathology. 2013; 63(6):826-32.

Barton ER, Morris L, Kawana M, Bish LT, Toursel T. Systemic administration of L-arginine benefits mdx skeletal muscle function. Muscle Nerve. 2005;32(6):751-60.
Benayoun BA, Pollina EA, Ucar D, Mahmoudi S, Karra K, Wong ED, et al. H3K4me3 breadth is linked to cell identity and transcriptional consistency. Cell. 2014;158(3):673-88.

Biressi S, Rando TA.Heterogeneity in the muscle satellite cell population. Semin Cell Dev Biol. 2010;21(8):845-54.

Birnkrant DJ, Bushby K, Bann CM, Apkon SD, Blackwell A, Brumbaugh D, et al. Diagnosis and management of Duchenne muscular dystrophy, part 1: diagnosis, and neuromuscular, rehabilitation, endocrine, and gastrointestinal and nutritional management. Lancet Neurol. 2018;17(3):251-67. 
Bladen CL, Salgado D, Monges S, Foncuberta ME, Kekou K, Kosma K, et al. The TREAT-NMD DMD Global Database: analysis of more than 7,000 Duchenne muscular dystrophy mutations. Hum Mutat. 2015;36(4):395-402.

Blankinship MJ, Gregorevic P, Allen JM, Harper SQ, Harper H, Halbert CL, et al. Efficient transduction of skeletal muscle using vectors based on adeno-associated virus serotype 6 . Mol Ther. 2004;10(4):671-8.

Bodensteiner JB, Engel AG. Intracellular calcium accumulation in Duchenne dystrophy and other myopathies: a study of 567,000 muscle fibers in 114 biopsies. Neurology. 1978;28(5): 439.

Boscolo Sesillo F, Fox D, Sacco A. Muscle Stem Cells Give Rise to Rhabdomyosarcomas in a Severe Mouse Model of Duchenne Muscular Dystrophy. Cell Rep. 2019;26(3):689-e6.

Bowles DE, McPhee SW, Li C, Gray SJ, Samulski JJ, Camp AS, et al. Phase 1 Gene Therapy for Duchenne Muscular Dystrophy Using a Translational Optimized AAV Vector. Mol Ther. 2012;20(2):443-55.

Boyer JG, Han S, Prasad V, Khalil H, Vagnozzi RJ, Molkentin JD. Satellite cell depletion in early adulthood attenuates muscular dystrophy pathogenesis. bioRxiv. 2019:857433.

Bulfield G, Siller WG, Wight PA, Moore KJ. X chromosome-linked muscular dystrophy $(\mathrm{mdx})$ in the mouse. Proc Natl Acad Sci USA. 1984;81(4):1189-92.

Bushby K, Finkel R, Birnkrant DJ, Case LE, Clemens PR, Cripe L, et al. Diagnosis and management of Duchenne muscular dystrophy, part 1: diagnosis, and pharmacological and psychosocial management. Lancet Neurol. 2010;9(1):77-93.

Campbell KP, Kahl SD. Association of dystrophin and an integral membrane glycoprotein. $\mathrm{Na}-$ ture. 1989;338(6212):259-62.

Campisi J. Aging, Cellular Senescence, and Cancer. Annu Rev Physiol. 2013;75(1):685-705.

Casuso RA, Huertas JR. The emerging role of skeletal muscle mitochondrial dynamics in exercise and ageing. Ageing Res Rev. 2020;58: 101025.

Chakkalakal JV, Stocksley MA, Harrison MA, Angus LM, Deschênes-Furry J, St-Pierre S, et al. Expression of utrophin A mRNA correlates with the oxidative capacity of skeletal muscle fiber types and is regulated by calcineurin/NFAT signaling. Proc Natl Acad Sci USA. 2003;100(13):7791-6.

Chal J, Oginuma M, Al Tanoury Z, Gobert B, Sumara O, Hick A, et al. Differentiation of pluripotent stem cells to muscle fiber to model Duchenne muscular dystrophy. Nat Biotechnol. 2015;33(9):962-9.

Chamberlain JS, Metzger J, Reyes M, Townsend D, Faulkner JA. Dystrophin-deficient $\mathrm{mdx}$ mice display a reduced life span and are susceptible to spontaneous rhabdomyosarcoma. FASEB J. 2007;21(9):2195-204.

Chan S, Head SI. The role of branched fibres in the pathogenesis of Duchenne muscular dystrophy. Exp Physiol. 2011;96(6):564-71.
Chang NC, Chevalier FP, Rudnicki MA. Satellite Cells in Muscular Dystrophy - Lost in Polarity. Trends Mol Med. 2016;22(6):479-96.

Chang NC, Sincennes MC, Chevalier FP, Brun CE, Lacaria M, Segalés J, et al. The Dystrophin Glycoprotein Complex Regulates the Epigenetic Activation of Muscle Stem Cell Commitment. Cell Stem Cell. 2018;22(5):755-e6.

Chapman J, Fielder E, Passos JF. Mitochondrial dysfunction and cell senescence: deciphering a complex relationship. FEBS Lett. 2019; 593(13): 1566-79.

Cooper RN, Tajbakhsh S, Mouly V, Cossu G, Buckingham $\mathrm{M}$, Butler-Browne GS. In vivo satellite cell activation via Myf5 and MyoD in regenerating mouse skeletal muscle. J Cell Sci. 1999;112(Pt 17):2895-901.

Cornelison DD, Wold BJ. Single-Cell Analysis of Regulatory Gene Expression in Quiescent and Activated Mouse Skeletal Muscle Satellite Cells. Dev Biol. 1997;191(2):270-83.

Cramer Z, Sadek J, Vazquez GG, Di Marco S, Pause A, Pelletier J, et al. eIF4A inhibition prevents the onset of cytokine-induced muscle wasting by blocking the STAT3 and iNOS pathways. Sci Rep. 2018;8(1):8414.

De Arcangelis V, Serra F, Cogoni C, Vivarelli E, Monaco L, Naro F. $\beta 1$-syntrophin modulation by miR-222 in mdx mice. PLoS One. 2010;5(8)

De Micheli AJ, Laurilliard EJ, Heinke CL, Ravichandran H, Fraczek P, Soueid-Baumgarten S, et al. Single-Cell Analysis of the Muscle Stem Cell Hierarchy Identifies Heterotypic Communication Signals Involved in Skeletal Muscle Regeneration. Cell Rep. 2020;30(10): 3583-3595e5.

Deconinck AE, Rafael JA, Skinner JA, Brown SC, Potter AC, Metzinger L, et al. Utrophin-dystrophin-deficient mice as a model for Duchenne muscular dystrophy. Cell. 1997;90(4):717-27.

Deconinck N, Tinsley J, De Backer F, Fisher R, Kahn D, Phelps S, et al. Expression of truncated utrophin leads to major functional improvements in dystrophin-deficient muscles of mice. Nat Med. 1997;3(11):1216-21.

Dell OS, Juan AH, Ko K-D, Naz F, Perovanovic J, et al. Single cell analysis of adult mouse skeletal muscle stem cells in homeostatic and regenerative conditions. Development. 2019; 146(12): dev174177.

Di Marco S, Mazroui R, Dallaire P, Chittur S, Tenenbaum SA, Radzioch D, et al. NF-kappa Bmediated MyoD decay during muscle wasting requires nitric oxide synthase mRNA stabilization, HuR protein, and nitric oxide release. Mol Cell Biol. 2005;25(15):6533-45.

Doherty TJ. Invited review: aging and sarcopenia. J Appl Physiol. 2003;95(4):1717-27.

Duan D. Systemic AAV Micro-dystrophin Gene Therapy for Duchenne Muscular Dystrophy. Mol Ther. 2018;26(10):2337-56.

Dumont NA, Wang YX, von Maltzahn J, Pasut A, Bentzinger CF, Brun CE, et al. Dystrophin expression in muscle stem cells regulates their polarity and asymmetric division. Nat Med. 2015;21(12):1455-63.
Emery AE, Muntoni F, Quinlivan RC. Duchenne muscular dystrophy. Oxford: Oxford University Press; 2015.

Ervasti JM, Ohlendieck K, Kahl SD, Gaver MG, Campbell KP. Deficiency of a glycoprotein component of the dystrophin complex in dystrophic muscle. Nature. 1990;345(6273):3159.

Faber RM, Hall JK, Chamberlain JS, Banks GB. Myofiber branching rather than myofiber hyperplasia contributes to muscle hypertrophy in mdx mice. Skelet Muscle. 2014;4:10.

Falzarano MS, Scotton C, Passarelli C, Ferlini A. Duchenne Muscular Dystrophy: From Diagnosis to Therapy. Molecules. 2015;20(10): $18168-84$.

Fearon K, Strasser F, Anker SD, Bosaeus I, Bruera E, Fainsinger RL, et al. Definition and classification of cancer cachexia: an international consensus. Lancet Oncol. 2011;12(5):489-95.

Fiacco E, Castagnetti F, Bianconi V, Madaro L, De Bardi M, Nazio F, et al. Autophagy regulates satellite cell ability to regenerate normal and dystrophic muscles. Cell Death Differ. 2016; 23(11):1839-49.

Fong PY, Turner PR, Denetclaw WF, Steinhardt RA. Increased activity of calcium leak channels in myotubes of Duchenne human and mdx mouse origin. Science. 1990;250(4981): 673-6.

Gao X, Han G, Yin H. Recent Advances in AONMediated Exon-Skipping Therapy for Duchenne Muscular Dystrophy. Springer; 2019. p. 339-54. Muscle Gene Therapy.

García-Prat L, Martínez-Vicente M, Perdiguero E, Ortet L, Rodríguez-Ubreva J, Rebollo E, et al. Autophagy maintains stemness by preventing senescence. Nature. 2016;529(7584): $37-42$.

Garcia-Prat L, Perdiguero E, Alonso-Martin S, Dell'Orso S, Ravichandran S, Brooks SR, et al. FoxO maintains a genuine muscle stem-cell quiescent state until geriatric age. Nat Cell Biol. 2020;22(11):1307-18.

Gregorevic P, Blankinship MJ, Allen JM, Crawford RW, Meuse L, Miller DG, et al. Systemic delivery of genes to striated muscles using adeno-associated viral vectors. Nat Med. 2004; 10(8):828-34.

Gurevich DB, Nguyen PD, Siegel AL, Ehrlich OV, Sonntag C, Phan JM, et al. Asymmetric division of clonal muscle stem cells coordinates muscle regeneration in vivo. Science. 2016; 353(6295):aad9969.

Guttridge DC, Mayo MW, Madrid LV, Wang CY, Baldwin AS Jr. NF-kappaB-induced loss of MyoD messenger RNA: possible role in muscle decay and cachexia. Science. 2000; 289(5488):2363-6.

Hayes MN, McCarthy K, Jin A, Oliveira ML, Iyer S, Garcia SP, et al. Vangl2/RhoA Signaling Pathway Regulates Stem Cell Self-Renewal Programs and Growth in Rhabdomyosarcoma. Cell Stem Cell. 2018;22(3):414-e6. 
He WA, Berardi E, Cardillo VM, Acharyya S, Aulino $\mathrm{P}$, Thomas-Ahner $\mathrm{J}$, et al. NF- $\mathrm{kB}$ mediated Pax7 dysregulation in the muscle microenvironment promotes cancer cachexia. J Clin Invest. 2013;123(11):4821-35.

Hernández-Hernández JM, García-González EG, Brun CE, Rudnicki MA. The myogenic regulatory factors, determinants of muscle development, cell identity and regeneration. Semin Cell Dev Biol. 2017;72:10-18.

Heslop L, Morgan JE, Partridge TA. Evidence for a myogenic stem cell that is exhausted in dystrophic muscle. J Cell Sci. 2000;113 (Pt 12): 2299.

Hoffman EP, Brown RH Jr., Kunkel LM. Dystrophin: the protein product of the Duchenne muscular dystrophy locus. Cell. 1987;51(6): 919-28.

Hood DA, Memme JM, Oliveira AN, Triolo M. Maintenance of Skeletal Muscle Mitochondria in Health, Exercise, and Aging. Annu Rev Physiol. 2019;81(1):19-41.

Hughes DC, Marcotte GR, Marshall AG, West DWD, Baehr LM, Wallace MA, et al. Age-related Differences in Dystrophin: Impact on Force Transfer Proteins, Membrane Integrity, and Neuromuscular Junction Stability. J Gerontol A Biol Sci Med Sci. 2017;72(5):640-

Hughes MC, Ramos SV, Turnbull PC, Rebalka IA, Cao A, Monaco CMF, et al. Early myopathy in Duchenne muscular dystrophy is associated with elevated mitochondrial $\mathrm{H}$. J Cachexia Sarcopenia Muscle. 2019;10(3):643-61.

Inaba S, Hinohara A, Tachibana M, Tsujikawa K, Fukada SI. Muscle regeneration is disrupted by cancer cachexia without loss of muscle stem cell potential. PLoS One. 2018;13(10): e0205467.

Joseph J, Cho DS, Doles JD. Metabolomic Analyses Reveal Extensive Progenitor Cell Deficiencies in a Mouse Model of Duchenne Muscular Dystrophy. Metabolites. 2018;8(4).

Kawabe Y, Wang YX, McKinnell IW, Bedford MT, Rudnicki MA. Carm1 regulates Pax7 transcriptional activity through MLL1/2 recruitment during asymmetric satellite stem cell divisions. Cell Stem Cell. 2012;11(3):33345.

Khan MA. Corticosteroid therapy in Duchenne muscular dystrophy. J Neurol Sci. 1993; 120(1):8-14.

Kharraz Y, Guerra J, Pessina P, Serrano AL, Munoz-Canoves P. Understanding the process of fibrosis in Duchenne muscular dystrophy. Biomed Res Int. 2014;2014:965631.

Khurana TS, Rosmarin AG, Shang J, Krag TO, Das S, Gammeltoft S. Activation of utrophin promoter by heregulin via the ets-related transcription factor complex GA-binding protein alpha/beta. Mol Biol Cell. 1999;10(6): 2075-86.

Kimmel JC, Hwang AB, Scaramozza A, Marshall WF, Brack AS. Aging induces aberrant state transition kinetics in murine muscle stem cells. Development. 2020;147(9):dev183855.
Kindstedt E, Holm CK, Sulniute R, MartinezCarrasco I, Lundmark R, Lundberg P. CCL11, a novel mediator of inflammatory bone resorption. Sci Rep. 2017;7(1):5334.

Koenig M, Hoffman E, Bertelson C, Monaco A, Feener C, Kunkel L. Complete cloning of the Duchenne muscular dystrophy (DMD) cDNA and preliminary genomic organization of the DMD gene in normal and affected individuals. Cell. 1987;50(3):509-17.

Koenig M, Monaco A, Kunkel L. The complete sequence of dystrophin predicts a rod-shaped cytoskeletal protein. Cell. 1988;53(2):219-28.

Koo T, Wood MJ. Clinical trials using antisense oligonucleotides in duchenne muscular dystrophy. Hum Gene Ther. 2013;24(5):479-88.

Kottlors M, Kirschner J. Elevated satellite cell number in Duchenne muscular dystrophy. Cell Tissue Res. 2010;340(3):541-8.

Kuang S, Kuroda K, Le Grand F, Rudnicki MA. Asymmetric self-renewal and commitment of satellite stem cells in muscle. Cell. 2007; 129(5):999-1010.

Latella L, Dall'Agnese A, Boscolo FS, Nardoni C, Cosentino M, Lahm A, et al. DNA damage signaling mediates the functional antagonism between replicative senescence and terminal muscle differentiation. Genes Dev. 2017; 31(7):648-59.

Le Grand F, Jones AE, Seale V, Scime A, Rudnicki MA. Wnt7a activates the planar cell polarity pathway to drive the symmetric expansion of satellite stem cells. Cell Stem Cell. 2009;4(6): $535-47$.

Lin C, Han G, Ning H, Song J, Ran N, Yi X, et al. Glycine Enhances Satellite Cell Proliferation, Cell Transplantation, and Oligonucleotide Efficacy in Dystrophic Muscle. Mol Ther. 2020;28(5):1339-58.

Lu A, Guo P, Wang L, Tseng C, Huard M, Allen $\mathrm{C}$, et al. Heterogenetic parabiosis between healthy and dystrophic mice improve the histopathology in muscular dystrophy. Sci Rep. 2020;10(1):7075

Ma JF, Sanchez BJ, Hall DT, Tremblay AK, Di Marco S, Gallouzi IE. STAT3 promotes IFNgamma/TNFalpha-induced muscle wasting in an NF-kappaB-dependent and IL-6-independent manner. EMBO Mol Med. 2017;9(5): 622-37.

Madaro L, Torcinaro A, De Bardi M, Contino FF, Pelizzola M, Diaferia GR, et al. Macrophages fine tune satellite cell fate in dystrophic skeletal muscle of mdx mice. PLoS Genet. 2019; 15(10):e1008408.

Mahoney WM, Jr., Gunaje J, Daum G, Dong XR, Majesky MW. Regulator of G-protein signaling -- 5 (RGS5) is a novel repressor of hedgehog signaling. PLoS One. 2013;8(4):e61421.

Maier F, Bornemann A. Comparison of the muscle fiber diameter and satellite cell frequency in human muscle biopsies. Muscle Nerve. 1999;22(5):578-83.

Manzur AY, Kuntzer T, Pike M, Swan AV. Glucocorticoid corticosteroids for Duchenne muscular dystrophy. Cochrane Database Syst Rev. 2008;1:CD003725.
Mauro A. Satellite cell of skeletal muscle fibers. J Biophys Biochem Cytol. 1961;9(2):493-5.

McCaffrey LM, Macara IG. Signaling pathways in cell polarity. Cold Spring Harb Perspect Biol. 2012;4(6):a009654.

McCoin CS, Knotts TA, Ono-Moore KD, Oort PJ, Adams SH. Long-chain acylcarnitines activate cell stress and myokine release in $\mathrm{C} 2 \mathrm{C} 12$ myotubes: calcium-dependent and -independent effects. Am J Physiol Endocrinol Metab. 2015;308(11):E990-E1000

McKinnell IW, Ishibashi J, Le Grand F, Punch VG, Addicks GC, Greenblatt JF, et al. Pax7 activates myogenic genes by recruitment of a histone methyltransferase complex. Nat Cell Biol. 2008;10(1):77-84.

Miura P, Jasmin BJ. Utrophin upregulation for treating Duchenne or Becker muscular dystrophy: how close are we? Trends Mol Med. 2006;12(3):122-9.

Mohiuddin M, Choi JJ, Lee NH, Jeong H, Anderson SE, Han WM, et al. Transplantation of Muscle Stem Cell Mitochondria Rejuvenates the Bioenergetic Function of Dystrophic Muscle. bioRxiv. 2020. 2020.04.17.017822.

Muntoni F, Fisher I, Morgan JE, Abraham D. Steroids in Duchenne muscular dystrophy: from clinical trials to genomic research. Neuromuscul Disord. 2002;12(Suppl 1):S162-5.

Nance ME, Shi R, Hakim CH, Wasala NB, Yue Y, Pan X, et al. AAV9 Edits Muscle Stem Cells in Normal and Dystrophic Adult Mice. Mol Ther. 2019;27(9):1568-85.

Naya FJ, Olson E. MEF2: a transcriptional target for signaling pathways controlling skeletal muscle growth and differentiation. Curr Opin Cell Biol. 1999;11(6):683-8.

Olguin HC, Yang Z, Tapscott SJ, Olwin BB. Reciprocal inhibition between Pax7 and muscle regulatory factors modulates myogenic cell fate determination. J Cell Biol. 2007;177(5):769-79.

Onopiuk M, Brutkowski W, Wierzbicka K, Wojciechowska S, Szczepanowska J, Fronk J, et al. Mutation in dystrophin-encoding gene affects energy metabolism in mouse myoblasts. Biochem Biophys Res Commun. 2009; 386(3):463-6.

Pant M, Sopariwala DH, Bal NC, Lowe J, Delfin DA, Rafael-Fortney J, et al. Metabolic dysfunction and altered mitochondrial dynamics in the utrophin-dystrophin deficient mouse model of duchenne muscular dystrophy. PLoS One. 2015;10(4):e0123875.

Peladeau C, Adam N, Bronicki LM, Coriati A, Thabet M, Al-Rewashdy $\mathrm{H}$, et al. Identification of therapeutics that target eEF1A2 and upregulate utrophin A translation in dystrophic muscles. Nat Commun. 2020;11(1): 1990.

Petrany MJ, Millay DP. Cell Fusion: Merging Membranes and Making Muscle. Trends Cell Biol. 2019;29(12):964-73.

Petrillo S, Pelosi L, Piemonte F, Travaglini L, Forcina L, Catteruccia M, et al. Oxidative stress in Duchenne muscular dystrophy: focus on the NRF2 redox pathway. Hum Mol Genet. 2017;26(14):2781-90. 
Petrof BJ, Shrager JB, Stedman HH, Kelly AM, Sweeney HL. Dystrophin protects the sarcolemma from stresses developed during muscle contraction. Proc Natl Acad Sci USA. 1993;90(8):3710-4.

Phillips HM, Murdoch JN, Chaudhry B, Copp AJ, Henderson DJ. Vangl2 acts via RhoA signaling to regulate polarized cell movements during development of the proximal outflow tract. Circ Res. 2005;96(3):292-9.

Rando TA, Disatnik M-H, Yu Y, Franco A. Muscle cells from mdx mice have an increased susceptibility to oxidative stress. Neuromuscul Disord. 1998;8(1):14-21.

Relaix F, Zammit PS. Satellite cells are essential for skeletal muscle regeneration: the cell on the edge returns centre stage. Development. 2012;139(16):2845.

Rocheteau P, Gayraud-Morel B, Siegl-Cachedenier I, Blasco MA, Tajbakhsh S. A subpopulation of adult skeletal muscle stem cells retains all template DNA strands after cell division. Cell. 2012;148(1--2):112-25.

Romanello V, Sandri M. Mitochondria quality control and muscle mass maintenance. Front Physiol. 2016;6:422.

Rosenberg AS, Puig M, Nagaraju K, Hoffman EP, Villalta SA, Rao VA, et al. Immune-mediated pathology in Duchenne muscular dystrophy. Sci Transl Med. 2015;7(299):299rv4.

Ryan MT, Hoogenraad NJ. Mitochondrial-nuclear communications. Annu Rev Biochem. 2007;76:701-22.

Ryder S, Leadley RM, Armstrong N, Westwood M, de Kock S, Butt T, et al. The burden, epidemiology, costs and treatment for Duchenne muscular dystrophy: an evidence review. Orphanet J Rare Dis. 2017;12(1):79.

Sacco A, Mourkioti F, Tran R, Choi J, Llewellyn M, Kraft P, et al. Short telomeres and stem cell exhaustion model Duchenne muscular dystrophy in $\mathrm{mdx} / \mathrm{mTR}$ mice. Cell. 2010;143(7): 1059-71.

Salmaninejad A, Valilou SF, Bayat H, Ebadi N, Daraei A, Yousefi M, et al. Duchenne muscular dystrophy: an updated review of common available therapies. Int J Neurosci. 2018; 128(9):854-64

Scholte HR, Busch HFM. Early changes of muscle mitochondria in duchenne dystrophy: Partition and activity of mitochondrial enzymes in fractionated muscle of unaffected boys and adults and patients. J Neurol Sci. 1980;45(2): 217-34.

Seale P, Sabourin LA, Girgis-Gabardo A, Mansouri A, Gruss P, Rudnicki MA. Pax7 Is Required for the Specification of Myogenic Satellite Cells. Cell. 2000;102(6):777-86.
Sharma N, Medikayala S, Defour A, Rayavarapu S, Brown KJ, Hathout Y, et al. Use of quantitative membrane proteomics identifies a novel role of mitochondria in healing injured muscles. J Biol Chem. 2012;287(36):30455-67.

Snijders T, Nederveen JP, McKay BR, Joanisse S, Verdijk LB, van Loon LJ, et al. Satellite cells in human skeletal muscle plasticity. Front Physiol. 2015;6:283.

Soleimani VD, Punch VG, Kawabe Y, Jones AE, Palidwor GA, Porter CJ, et al. Transcriptional dominance of Pax7 in adult myogenesis is due to high-affinity recognition of homeodomain motifs. Dev Cell. 2012;22(6):1208-20.

Sousa-Victor P, Gutarra S, Garcia-Prat L, Rodriguez-Ubreva J, Ortet L, Ruiz-Bonilla V, et al. Geriatric muscle stem cells switch reversible quiescence into senescence. Nature. 2014; 506(7488):316-21.

Strassmann G, Fong M, Kenney JS, Jacob CO. Evidence for the involvement of interleukin 6 in experimental cancer cachexia. J Clin Invest. 1992;89(5):1681-4.

Sugihara H, Teramoto N, Nakamura K, Shiga T, Shirakawa T, Matsuo M, et al. Cellular senescence-mediated exacerbation of Duchenne muscular dystrophy. Sci Rep. 2020;10(1): 16385.

Tierney MT, Sacco A. Satellite Cell Heterogeneity in Skeletal Muscle Homeostasis. Trends Cell Biol. 2016;26(6):434-44.

Tinsley J, Potter AC, Phelps SR, Fisher R, Trickett JI, Davies KE. Amelioration of the dystrophic phenotype of $\mathrm{mdx}$ mice using a truncated utrophin transgene. Nature. 1996;384(6607): 349-53.

Tinsley J, Deconinck N, Fisher R, Kahn D, Phelps S, Gillis J-M, et al. Expression of full-length utrophin prevents muscular dystrophy in mdx mice. Nat Med. 1998;4(12):1441-4.

Tisdale MJ. Mechanisms of Cancer Cachexia. Physiol Rev. 2009;89(2):381-410.

Troy A, Cadwallader AB, Fedorov Y, Tyner K, Tanaka KK, Olwin BB. Coordination of satellite cell activation and self-renewal by Parcomplex-dependent asymmetric activation of p38alpha/beta MAPK. Cell Stem Cell. 2012; 11(4):541-53.

Vila MC, Rayavarapu S, Hogarth MW, Van der Meulen JH, Horn A, Defour A, et al. Mitochondria mediate cell membrane repair and contribute to Duchenne muscular dystrophy. Cell Death Differ. 2017;24(2):330-42.

Wanet A, Arnould T, Najimi M, Renard P. Connecting Mitochondria, Metabolism, and Stem Cell Fate. Stem Cells Dev. 2015;24(17):195771.
Wang Y, Marino-Enriquez A, Bennett RR, Zhu M, Shen Y, Eilers G, et al. Dystrophin is a tumor suppressor in human cancers with myogenic programs. Nat Genet. 2014;46(6):6016.

Wang YX, Feige P, Brun CE, Hekmatnejad B, Dumont NA, Renaud JM, et al. EGFR-Aurka Signaling Rescues Polarity and Regeneration Defects in Dystrophin-Deficient Muscle Stem Cells by Increasing Asymmetric Divisions. Cell Stem Cell. 2019;24(3):419-32 e6.

Webster MT, Manor U, Lippincott-Schwartz J, Fan CM. Intravital Imaging Reveals Ghost Fibers as Architectural Units Guiding Myogenic Progenitors during Regeneration. Cell Stem Cell. 2016;18(2):243-52.

Williams G, Brown T, Becker L, Prager M, Giroir BP. Cytokine-induced expression of nitric oxide synthase in $\mathrm{C} 2 \mathrm{C} 12$ skeletal muscle myocytes. Am J Physiol. 1994;267(4 Pt 2):R10205.

Wu Y, Griffin EE. Regulation of Cell Polarity by PAR-1/MARK Kinase. Curr Top Dev Biol. 2017;123:365-97.

Xi H, Langerman J, Sabri S, Chien P, Young CS, Younesi S, et al. A Human Skeletal Muscle Atlas Identifies the Trajectories of Stem and Progenitor Cells across Development and from Human Pluripotent Stem Cells. Cell Stem Cell. 2020;27(1):1586.e10-7.

$\mathrm{Xu}$ J, Liu D, Yin H, Tong H, Li S, Yan Y. Fatty acids promote bovine skeletal muscle satellite cell differentiation by regulating ELOVL3 expression. Cell Tissue Res. 2018;373(2):499_ 508

Yablonka-Reuveni Z, Anderson JE. Satellite cells from dystrophic $(\mathrm{mdx})$ mice display accelerated differentiation in primary cultures and in isolated myofibers. Dev Dyn. 2006;235(1): 203-12.

Yamashita K, Suzuki A, Satoh Y, Ide M, Amano $\mathrm{Y}$, Masuda-Hirata M, et al. The 8th and 9th tandem spectrin-like repeats of utrophin cooperatively form a functional unit to interact with polarity-regulating kinase PAR-1b. Biochem Biophys Res Commun. 2010;391(1): 812-7.

Yin H, Price F, Rudnicki MA. Satellite cells and the muscle stem cell niche. Physiol Rev. 2013; 93(1):23-67.

Zammit PS, Relaix F, Nagata Y, Ruiz AP, Collins CA, Partridge TA, et al. Pax7 and myogenic progression in skeletal muscle satellite cells. J Cell Sci. 2006;119(Pt 9):1824-32.

Zhang H, Ryu D, Wu Y, Gariani K, Wang X, Luan $\mathrm{P}$, et al. $\mathrm{NAD}(+)$ repletion improves mitochondrial and stem cell function and enhances life span in mice. Science. 2016;352(6292): 1436-43. 